\title{
Profile of French Community-Dwelling Older Adults Supplemented with Vitamin D: Findings and Lessons
}

Bruno Fantino · Olivier Beauchet · Séverine Savignat · Béatrice Bouvard · Erick Legrand · Cédric Annweiler

Received: March 25, 2011 / Published online: May 19, 2011

(C) Springer Healthcare 2011

\section{ABSTRACT}

Introduction: The vast majority of older French adults exhibit some degree of hypovitaminosis D. The objective of this cross-sectional study was to determine the rate and the reasons for vitamin D prescription among older French adult community dwellers. Methods: Vitamin D supplementation was systematically assessed among 1876 French community dwellers aged $\geq 65$ years. Theoretical indications for vitamin D supplementation were collected, ie, the causes of hypovitaminosis D (older age, male gender, kidney failure, undernutrition, polymorbidity) or its clinical complications (vertebral or nonvertebral fractures, gait disturbances, history

Bruno Fantino - Olivier Beauchet · Séverine Savignat . Cédric Annweiler $(\triangle)$

Department of Internal Medicine and Geriatrics, Angers University Hospital, 49933 Angers Cedex 9, France.

Email: CeAnnweiler@chu-angers.fr

Bruno Fantino

Health Examination Center, CNAMTS, Lyon, France

Séverine Savignat

Department of Primary Care, Angers Medical School, Angers, France

Béatrice Bouvard · Erick Legrand

Department of Rheumatology, Angers University

Hospital, Angers, France of falls, muscle weakness, and cognitive impairment). Results: In total, $13.8 \%$ of the subjects $(n=258)$ had vitamin D supplementation. They were more often malnourished $(P=0.002)$, exhibited polymorbidity $(P<0.001)$ and muscle weakness $(P<0.001)$, and had a history of vertebral fractures $(P<0.001)$, non-vertebral fractures $(P<0.001)$, and accidental falls $(P<0.001)$. Vitamin D supplementation was explained by the number of complications of hypovitaminosis D (odds ratio $[\mathrm{OR}]=1.61$, $P<0.001$ ) including vertebral fractures (adjusted $\mathrm{OR}=1.49, P=0.007)$, non-vertebral fractures (adjusted $\mathrm{OR}=1.74, P=0.026$ ), accidental falls (adjusted $\mathrm{OR}=1.44, P=0.015$ ), and muscle weakness (adjusted $\mathrm{OR}=3.96, P<0.001$ ), but not by the number of causes of hypovitaminosis D $(P=0.464)$. Conclusion: Even if vitamin D supplementation is selected well for appropriate patients, the rate of supplementation remains insufficient in France, and probably comes too late, ie, at the stage of complications of hypovitaminosis D. These findings should encourage physicians to supplement vitamin D more often and sooner in their elderly patients.

Keywords: vitamin D; older adults; supplementation 


\section{INTRODUCTION}

Between $70 \%$ to $90 \%$ of French communitydwelling adults aged $\geq 65$ years exhibit some degree of hypovitaminosis D. ${ }^{1-3}$ Hypovitaminosis D is associated with poor health outcomes among older adults including bone disease, neuromuscular impairments, and gait disturbances. ${ }^{4-6}$ Prevention of these clinical events depends on the correction of vitamin D status. ${ }^{7}$ It is now acknowledged that the inadequate vitamin $\mathrm{D}$ intakes in elderly subjects may not be efficiently handled with dietary measures or food supplementation alone. ${ }^{7}$ This highlights the central role of physician-prescribed vitamin D supplementation, especially in France where food fortification and one-a-day vitamins supply minor intakes of vitamin D. ${ }^{8}$ Although there is a growing body of literature on vitamin $\mathrm{D}$ and aging, little is known about the rate of supplementation in France, and about the reasons that lead primary care physicians to prescribe vitamin $\mathrm{D}$ supplementation to their elderly patients. The objective of our study was to determine whether the rate of supplementation covered the needs of older French community-dwelling adults, and to identify the clinical reasons for vitamin D prescription among this population.

\section{MATERIALS AND METHODS}

\section{Subjects}

Between July 2008 and October 2009, 1876 community-dwelling subjects aged $\geq 65$ years (mean age $70.3 \pm 0.2$ years; $50.4 \%$ men) were recruited in eight French health centers localized in Eastern France during a free medical examination. Exclusion criteria for this cross-sectional study included age $<65$ years, institutionalization, the inability to understand and speak French, and a history of acute medical illness during the past month.

\section{Clinical Assessment}

Vitamin D supplementation was noted from the primary care physician's prescription, whatever the dosage schedule or route of administration, and regardless of the date of commencement.

We considered as theoretical indications for vitamin D supplementation either the causes of hypovitaminosis D (ie, older age $>70$ years, male gender, kidney failure, undernutrition, polymorbidity) $)^{1,9}$ or its clinical complications (ie, vertebral or non-vertebral fractures, gait disturbances, previous falls, muscle weakness, and cognitive impairment). ${ }^{4-6}$

A systematic standardized questionnaire gathered information about the number of drugs taken per day ( $\geq$ five drugs excluding vitamin $\mathrm{D}$ defined polymorbid conditions), height at 20 years of age, history of accidental falls over the past year, and non-vertebral fractures. History of vertebral fractures was defined by the loss of at least $3 \mathrm{~cm}$ of height since the age of 20 years, ${ }^{10}$ and undernutrition by a body mass index $<21 \mathrm{~kg} / \mathrm{m}^{2}{ }^{11}$ Gait disturbances were defined by a timed up-and-go test $\geq 14$ seconds, ${ }^{12}$ and muscle weakness as being in the worst tertile of handgrip strength measured with a handheld dynamometer (Jamar, SammonsPreston, Bolingbrook, IL). Cognitive impairment was defined by impaired performance on the clock-drawing test. ${ }^{13}$ Finally, serum creatinine concentration was measured to assess renal function. Our budget was limited, and only the first 415 patients had a blood test. Kidney failure was defined by creatinine clearance $<60 \mathrm{~mL} / \mathrm{min}$ using the Cockcroft formula. 


\section{Statistics}

The subjects' baseline characteristics were summarized using means and standard deviations or frequencies and percentages, as appropriate. Normality of data distribution was checked using a skewness-kurtosis test. As the number of patients included was higher than 40 for each group, no transformations were applied to the variables of interest. Comparisons between groups were performed using the Chi-square test or the independent samples t-test, as appropriate.

Table 1. Characteristics and comparison of the subjects $(n=1876)$ separated into two groups based on vitamin D supplementation.

\begin{tabular}{|c|c|c|c|c|c|}
\hline & $\begin{array}{c}\text { Total cohort } \\
(n=1876)\end{array}$ & $\begin{array}{c}\text { Proportion (\%) } \\
\text { of vitamin D } \\
\text { supplementation }\end{array}$ & $\begin{array}{c}\text { Vitamin D } \\
\text { supplementation s } \\
(n=258)\end{array}$ & $\begin{array}{c}\text { No vitamin D } \\
\text { supplementation } \\
\quad(n=1618) \\
\end{array}$ & $P$-value* \\
\hline \multicolumn{6}{|l|}{ Causes of hypovitaminosis D } \\
\hline Age $>70, n(\%)$ & $743(39.6)$ & 25.8 & $192(74.4)$ & $551(34.1)$ & 0.146 \\
\hline Male, $n(\%)$ & $946(50.4)$ & 3.3 & $29(11.2)$ & $917(56.7)$ & $<0.001$ \\
\hline Kidney failure, ${ }^{\dagger} \mathrm{n}(\%)(\mathrm{n}=415)$ & $149(35.9)$ & 14.1 & $21(36.2)$ & $118(33.1)$ & 0.926 \\
\hline Undernutrition, ${ }^{\ddagger} n(\%)$ & $126(6.7)$ & 23.0 & $29(11.2)$ & $97(6.0)$ & 0.002 \\
\hline Polymorbidity, $n(\%)$ & $451(24.0)$ & 20.6 & $93(36.0)$ & $358(22.1)$ & $<0.001$ \\
\hline \multicolumn{6}{|l|}{ Clinical complications of hypovitaminosis D } \\
\hline History of vertebral fracture, ${ }^{\prime}$ (\%) & $890(47.4)$ & 18.3 & $163(63.2)$ & $727(44.9)$ & $<0.001$ \\
\hline History of non vertebral fracture, $n(\%)$ & $108(5.8)$ & 29.6 & $32(12.4)$ & $76(4.7)$ & $<0.001$ \\
\hline Gait disturbances, ${ }^{*} n(\%)$ & $178(9.5)$ & 17.4 & $31(12.0)$ & $147(9.1)$ & 0.136 \\
\hline History of accidental falls, $n(\%)$ & $714(38.1)$ & 19.5 & $139(53.9)$ & $575(35.5)$ & $<0.001$ \\
\hline Weakness,** $n(\%)$ & $615(33.0)$ & 27.0 & $166(64.8)$ & $449(28.0)$ & $<0.001$ \\
\hline Cognitive impairment, ${ }^{\dagger \dagger} n(\%)$ & $483(25.7)$ & 14.1 & $68(26.4)$ & $415(25.6)$ & 0.809 \\
\hline \multicolumn{6}{|c|}{ Indications for vitamin D supplementation } \\
\hline Total number $(/ 11)$, mean $\pm S D$ & $2.97 \pm 0.08$ & - & $3.67 \pm 0.88$ & $2.97 \pm 0.08$ & 0.440 \\
\hline $\begin{array}{l}\text { Number of causes of hypovitaminosis } \\
D(/ 5), \text { mean } \pm S D\end{array}$ & $1.55 \pm 0.51$ & - & $2.00 \pm 0.58$ & $1.55 \pm 0.05$ & 0.460 \\
\hline $\begin{array}{l}\text { Number of clinical complications of } \\
\text { hypovitaminosis } \mathrm{D}(/ 6) \text {, mean } \pm \mathrm{SD}\end{array}$ & $1.59 \pm 003$ & - & $2.32 \pm 0.08$ & $1.48 \pm 0.03$ & $<0.001$ \\
\hline \multicolumn{6}{|l|}{ SD, standard deviation. } \\
\hline \multicolumn{6}{|c|}{$\begin{array}{l}{ }^{*} \text { Comparisons of subjects with vitamin D supplementation with subjects without vitamin D supplementation based on the } \\
\text { independent samples t-test or Chi-square test, as appropriate. }\end{array}$} \\
\hline \multicolumn{6}{|c|}{ †Creatinine clearance $<60 \mathrm{~mL} / \mathrm{min}$; creatinine clearance calculated using Cockcroft formula (ie, [(140-age years) $\mathrm{x}$ weight } \\
\hline \multicolumn{6}{|c|}{$\mathrm{kg} /$ creatinine $\mathrm{mol} / \mathrm{l}] \mathrm{x} 1.04$ for women, and x1.25 for men). } \\
\hline \multicolumn{6}{|l|}{$¥$ Body mass index $<21 \mathrm{~kg} / \mathrm{m}^{2}$. } \\
\hline \multicolumn{6}{|c|}{ §Defined by a number of drugs taken per day $>4$ after subtraction of vitamin $D$ supplementation. } \\
\hline \multicolumn{6}{|c|}{ ||Loss of at least $3 \mathrm{~cm}$ of height since the age of 20 years. } \\
\hline \multicolumn{6}{|c|}{ Obtained from a systematic standardized questionnaire. } \\
\hline \multicolumn{6}{|l|}{ \#Timed up-and-go test $\geq 14$ seconds. } \\
\hline \multirow{2}{*}{\multicolumn{6}{|c|}{$\begin{array}{l}\text { **Worst tertile of handgrip strength; handgrip strength was calculated as the mean value of } 3 \text { repeated strength } \\
\text { measurements of the dominant upper limb. }\end{array}$}} \\
\hline & & & & & \\
\hline \multicolumn{6}{|l|}{ ††Impaired clock-drawing test. } \\
\hline$P$ significant $($ ie, $P<0.05)$ ir & & & & & \\
\hline
\end{tabular}


Secondly, univariate and multiple (ie, adjusted model, and stepwise backward model) logistic regressions were used to examine the association between the indications for vitamin D supplementation (independent variable) and vitamin D supplementation (dependent variable) while adjusting for the same category of indications (ie, causes or complications of hypovitaminosis D). $P$-values $<0.05$ were considered significant. Statistical analyses were performed with the use of the SPSS software (version 17.0; SPSS, Inc., Chicago, IL).

\section{Standard Protocol Approvals, Registrations, and Patient Consents}

Participants in the study were included only after having given their written informed consent for research. The study was conducted in accordance with the ethical standards set forth in the Helsinki Declaration (1983). The entire study protocol was approved by the local Ethical Committee.

\section{RESULTS}

Among our cohort of community-dwelling older adults, $13.8 \%$ ( $n=258,11.2 \%$ male) had vitamin $\mathrm{D}$ supplementation. They were more often malnourished $(P=0.002)$, and more often exhibited polymorbidity $(P<0.001)$ and muscle weakness $(P<0.001)$ (Table 1$)$. In addition, they more often had a history of vertebral fractures $(P<0.001)$, non-vertebral fractures $(P<0.001)$, and accidental falls $(P<0.001)$ (Table 1$)$. Table 1 also shows the proportion of participants receiving vitamin $D$ supplementation according to potential indications. The rate of supplementation was low in each case, reaching only $29.6 \%$ in best-case scenario.

Table 2 displays the results of logistic regressions. Vitamin D supplementation was explained by a history of vertebral fractures (odds ratio $[\mathrm{OR}]=1.49, P=0.007$ ), non-vertebral fractures $(\mathrm{OR}=1.74, P=0.026)$ and accidental falls (OR=1.44, $P=0.015)$, and by muscle weakness $(\mathrm{OR}=3.96, P<0.001)$ and polymorbidity $(\mathrm{OR}=9.29$, $P=0.070$ ) (Table 2). Finally, logistic regression showed that the more complications of hypovitaminosis $\mathrm{D}$ there were, the more vitamin D supplementation we observed (OR=1.61 [95\% CI: 1.46-1.78], $P<0.001)$ although the number of causes of hypovitaminosis D was not significantly associated with supplementation (OR=1.47 [95\% CI: 0.52-4.13], $P=0.464)$.

\section{DISCUSSION}

Our results showed that the rate of vitamin D supplementation was low among older French community-dwelling adults, reaching only $13.8 \%$ of the cohort, and ranging between $3.3 \%$ and $29.6 \%$ of subjects exhibiting some indications for supplementation. This result was coherent with previous research that found a $13 \%$ rate of supplementation among older Belgian adults living in urban areas, ${ }^{14}$ or a $15 \%$ rate of treatment among Dutch patients one year after an osteoporotic fracture. ${ }^{15}$

Even if this quantitative aspect was much lower than the $70 \%$ to $90 \%$ rate of hypovitaminosis D and should challenge the French health policy, our findings also showed that older adults receiving supplementation were well-chosen as illustrated by strong associations of theoretical indications for vitamin D supplementation with concrete supplementation (Table 2). Nevertheless, it seems that primary care physicians prescribed vitamin D too late, as not the causes but the complications of hypovitaminosis D mainly lead to supplementation (Table 3 ). In addition, we found that clinical criteria for supplementation decisions were the most recognized (ie, history 
Table 2. Univariate and multiple* logistic regressions showing the cross-sectional association between vitamin $\mathrm{D}$ supplementation (dependent variable) and the different indications for vitamin D supplementation (independent variables) $(n=1876)$.

\begin{tabular}{|c|c|c|c|c|c|c|c|c|c|}
\hline & \multicolumn{9}{|c|}{ Vitamin D supplementation } \\
\hline & \multicolumn{3}{|c|}{ Unadjusted model } & \multicolumn{3}{|c|}{ Adjusted model* } & \multicolumn{3}{|c|}{ Stepwise backward model* } \\
\hline & OR & $95 \% \mathrm{CI}$ & $P$-value & OR & $95 \% \mathrm{CI}$ & $P$-value & OR & $95 \% \mathrm{CI}$ & $P$-value \\
\hline \multirow{2}{*}{\multicolumn{10}{|c|}{$\begin{array}{l}\text { Causes of } \\
\text { hypovitaminosis D }\end{array}$}} \\
\hline & & & & & & & & & \\
\hline Age $>70$ years & 4.63 & $0.48-44.89$ & 0.186 & 3.33 & $0.28-40.07$ & 0.344 & - & - & - \\
\hline Male & 0.04 & $0.02-0.06$ & $<0.001$ & 0.39 & $0.03-4.45$ & 0.446 & - & - & - \\
\hline Kidney failure $^{\dagger}$ & 0.89 & $0.08-9.92$ & 0.926 & 0.64 & $0.05-7.87$ & 0.730 & - & - & - \\
\hline Undernutrition $^{\ddagger}$ & 1.99 & $1.28-3.08$ & 0.002 & 0.00 & $0.00-$ & 0.998 & - & - & - \\
\hline Polymorbidity ${ }^{\S}$ & 1.98 & $1.50-2.63$ & $<0.001$ & 8.69 & $0.77-98.85$ & 0.081 & 9.29 & $0.83-103.80$ & 0.070 \\
\hline \multicolumn{10}{|l|}{$\begin{array}{l}\text { Clinical complications of } \\
\text { hypovitaminosis D }\end{array}$} \\
\hline $\begin{array}{l}\text { History of vertebral } \\
\text { fracture }^{\|}\end{array}$ & 2.10 & $1.60-2.76$ & $<0001$ & 1.55 & $1.16-2.08$ & 0.003 & 1.49 & $1.12-2.00$ & 0.007 \\
\hline $\begin{array}{l}\text { History of non } \\
\text { vertebral fracture }\end{array}$ & 2.87 & $1.86-4.44$ & $<0.001$ & 1.71 & $1.04-2.79$ & 0.033 & 1.74 & $1.07-2.84$ & 0.026 \\
\hline Gait disturbances & 1.37 & $0.91-2.06$ & 0.137 & 0.81 & $0.52-1.27$ & 0.354 & - & - & - \\
\hline $\begin{array}{l}\text { History of accidental } \\
\text { falls }\end{array}$ & 2.12 & $1.63-2.76$ & $<0.001$ & 1.47 & $1.09-1.97$ & 0.011 & 1.44 & $1.07-1.93$ & 0.015 \\
\hline Weakness $^{* *}$ & 4.75 & $3.59-6.28$ & $<0.001$ & 4.07 & $3.04-5.46$ & $<0.001$ & 3.96 & $2.96-5.29$ & $<0.001$ \\
\hline Cognitive impairment $^{\dagger \dagger}$ & 1.04 & $0.77-1.40$ & 0.809 & 0.84 & $0.61-1.16$ & 0.283 & - & - & - \\
\hline
\end{tabular}

OR, odds ratio; CI, confidence interval.

*Separated analyses with adjustment for the same category of indications for vitamin D supplementation (ie, causes or complications of hypovitaminosis D).

†Creatinine clearance $<60 \mathrm{~mL} / \mathrm{min}$.

$\neq$ Body mass index $<21 \mathrm{~kg} / \mathrm{m} 2$.

||Defined by a number of drugs taken per day $>4$ excluding vitamin D.

$\S$ Loss of at least $3 \mathrm{~cm}$ of height since the age of 20 years.

gTimed up-and-go test $\geq 14$ seconds.

\#Obtained from a systematic standardized questionnaire.

${ }^{* *}$ Worst tertile of handgrip strength of the dominant upper limb.

t†Impaired clock-drawing test performance.

OR significant $($ ie, $\mathrm{P}<0.05)$ indicated in bold.

Table 3. Logistic regression showing the cross-sectional association between vitamin D supplementation (dependent variable) and the number of indications for vitamin D supplementation (independent variables) $(n=1876)$.

\begin{tabular}{llll}
\hline & \multicolumn{3}{c}{ Vitamin D supplementation } \\
\cline { 2 - 5 } & OR & 95\% CI & $P$-value \\
\hline Total number of indications for vitamin D supplementation $(/ 11)$ & 1.29 & $0.67-2.48$ & 0.443 \\
Number of causes of hypovitaminosis D $(/ 5)$ & 1.47 & $0.52-4.13$ & 0.464 \\
Number of clinical complications of hypovitaminosis D $(/ 6)$ & $\mathbf{1 . 6 1}$ & $\mathbf{1 . 4 6 - 1 . 7 8}$ & $<\mathbf{0 . 0 0 1}$ \\
\hline
\end{tabular}

OR, odds ratio; CI, confidence interval. 
of fractures and falls, muscle weakness), ${ }^{4}$ while newer criteria such as cognitive impairment ${ }^{5}$ were not associated with vitamin D supplementation. The main reasons could be a failure in communication campaigns, as well as a delayed change in prescribing behavior.

Limitations of this study included the lack of measurement of 25-hydroxyvitamin D concentration, which would have confirmed the indication for supplementation. Nevertheless, the fact that $77.6 \%$ of studied subjects presented with at least one clinical manifestation of hypovitaminosis D (which was concordant with the prevalence of hypovitaminosis $\mathrm{D}$ in older French community-dwellers ${ }^{1-3}$ ) justified our approach and confirmed the representativeness of our cohort. In addition, we did not assess the dosage of vitamin D supplementation, although it has been suggested that there is a vitamin D dosage threshold below which supplements are insufficient in the elderly. ${ }^{16}$ Further studies are needed to determine the rate of elderly individuals receiving at least $800 \mathrm{UI}$ of vitamin D per day.

\section{CONCLUSION}

In conclusion, even if vitamin D supplementation is selected well for appropriate patients, the rate of supplementation remains insufficient in France, and probably comes too late, ie, at the stage of complications of hypovitaminosis D. These findings should encourage primary care physicians to supplement more often and sooner in their elderly patients.

\section{ACKNOWLEDGMENTS}

Dr. Annweiler had full access to the data in the study and takes responsibility for the integrity of the data and the accuracy of the data analyses. Study concept and design: Annweiler. Acquisition of data: Fantino and Savignat.
Analysis and interpretation of data: Annweiler, Savignat and Beauchet. Drafting of the manuscript: Annweiler, Fantino, Beauchet, and Savignat. Critical revision of the manuscript for important intellectual content: Bouvard and Legrand. Obtained funding: Fantino. Statistical expertise: Annweiler and Beauchet. Administrative, technical, or material support: Beauchet and Fantino. Study supervision: Annweiler. We are grateful to the participants for their cooperation. Prof. Fantino reports no conflicts of interest. He has no relevant financial interest in this manuscript. Prof. Beauchet serves as an unpaid consultant for Ipsen Pharma company. He has no relevant financial interest in this manuscript. Dr Savignat reports no conflicts of interest. She has no relevant financial interest in this manuscript. Dr Bouvard reports no conflicts of interest. She has no relevant financial interest in this manuscript. Prof. Legrand reports no conflicts of interest. He has no relevant financial interest in this manuscript. Dr Annweiler serves as an unpaid consultant for Ipsen Pharma company. He has no relevant financial interest in this manuscript.

\section{REFERENCES}

1. Chapuy MC, Preziosi P, Maamer M, et al. Prevalence of vitamin D insufficiency in an adult normal population. Osteoporos Int. 1997; 7:439-443.

2. Annweiler C, Souberbielle JC, Schott AM, De Decker L, Berrut G, Beauchet O. Vitamin D in the elderly: 5 points to remember. Geriatr Psychol Neuropsychiatr. 2011. In press.

3. Bruyère $\mathrm{O}$, Malaise $\mathrm{O}$, Neuprez A, Collette $\mathrm{J}$, Reginster JY. Prévalence élevée de la carence en vitamine D chez la femme ménopausée en Europe et principalement en France: analyse d'une cohorte de 8532 sujets. Revue du Rhumatisme. 2006;73:1052. [Article in French]

4. Annweiler C, Schott AM, Berrut G, Fantino B, Beauchet O. Vitamin D-related changes in physical 
performance: a systematic review. J Nutr Health Aging. 2009;13:893-898.

5. Annweiler C, Allali G, Allain P, et al. Vitamin D and cognitive performance in adults: a systematic review. Eur J Neurol. 2009;16:1083-1089.

6. Annweiler C, Montero-Odasso M, Schott AM, Berrut G, Fantino B, Beauchet O. Fall prevention and vitamin $\mathrm{D}$ in the elderly: an overview of the key role of the non-bone effects. J Neuroeng Rehabil. 2010;7:50.

7. Nowson C. Vitamin D status of Australians: Impact of changes to mandatory fortification of margarine with vitamin D. In: Australia and New Zealand Food Authority. Canberra, 2001.

8. Dupuy C. Le rôle de la vitamine D dans la nutrition des sujets âgés. In: Gérontologie et société. Ed. Fondation Nationale de Gérontologie. Paris, 2010. [Article in French]

9. Langlois K, Greene-Finestone L, Little J, Hidiroglou $\mathrm{N}$, Whiting $\mathrm{S}$. Les niveaux de vitamine $\mathrm{D}$ chez les Canadiens selon les résultats de l'Enquête canadienne sur les mesures de la santé, 2007-2009. In: Statistique Canada, Rapports sur la santé 2010. Montréal; 2010:51-60. [Article In French]

10. Lorthiois J, Skowronski V, Fleury M, Gauvain JB. Screening elderly at fracture-risk eligible to a treatment. Les cahiers de l'année gérontologique. 2010;2:71-79. [Article in French]

11. Management strategy of protein-energy malnutrition in the elderly. French National Authority for Health (online). Available at: http://www.has-sante.fr/ portail/upload/docs/application/pdf/malnutrition_ elderly_guidelines.pdf. Accessed July 14, 2010.

12. Okumiya K, Matsubayashi K, Nakamura T, et al. The timed "up \& go" test is a useful predictor of falls in community-dwelling older people. J Am Geriatr Soc. 1998;46:928-930.

13. Agrell B, Dehlin O. The clock-drawing test. Age Ageing. 1998;27:399-403.

14. Boüüaert C, Vanmeerbeek $\mathrm{M}$, Burette $\mathrm{P}$, et al. Vitamin $\mathrm{D}$ deficiency in elderly men living in urban areas, at home or in institutions. Presse Med. 2008;37:187-190.

15. Panneman MJ, Lips $P$, Sen SS, Herings RM. Undertreatment with anti-osteoporotic drugs after hospitalization for fracture. Osteoporos Int. 2004;15:120-124.

16. Ross AC, Manson JE, Abrams SA, et al. The 2011 report on dietary reference intakes for calcium and vitamin D from the Institute of Medicine: what clinicians need to know. J Clin Endocrinol Metab. 2011;96:53-58. 